\title{
LATIHAN HEAVY BAG THRUST TERHADAP TOLAK PELURU
}

\author{
HEAVY BAG TRAINING THRUST AGAINST SHOT PUT \\ Ahmad Yani Datuela, Hartono Hadjarati, Nurhayati Liputo \\ Jurusan Pendidikan Kepelatihan Olahraga Universitas Negeri Gorontalo \\ Kontak Penulis: hartonohadjarati@ung.ac.id
}

\begin{abstract}
ABSTRAK
Penelitian ini bertujuan mengetahui pengaruh latihan heavy bag thrust terhadap kemampuan tolak peluru siswa kelas ekstra kurikuler SMP Negeri 5 Kota Gorontalo. Populasi dalam penelitian ini adalah seluruh siswa ekstrakulikuler SMP Negeri 5 Kota Gorontalo berjumlah 27 orang. Sampel penelitian ini sebanyak 23 orang, diambil menggunakan teknik purposive random sampling. Metode penelitian ini menggunakan eksperimen dengan desain penelitian one group pre-test and post-test design. Data dikumpulkan menggunakan pre-test dan post-test. Kemudian dianalisis dengan menggunakan statistik uji t. Penelitian ini menemukan bahwa latihan heavy bag thrust memiliki pengaruh yang signifikan terhadap peningkatan kemampuan tolak peluru. Penelitian ini diharapkan dapat menambah refrensi seorang pelatih untuk meningkatkan kemampuan tolak peluru atlet asuhannya.
\end{abstract}

Kata kunci: heavy bag thrust; tolak peluru

\begin{abstract}
This study aims to determine the effect of heavy bag thrust training on the ability to shot put in extra curricular classes at SMP Negeri 5 Gorontalo City. The population in this study were all extracurricular students of SMP Negeri 5 Gorontalo City totaling 27 people. The sample of this study were 23 people, taken using purposive random sampling technique. This research method uses experiments with one group pre-test and post-test design research designs. Data was collected using pre-test and post-test. Then analyzed using t test statistics. This study found that heavy bag thrust training had a significant effect on increasing shot put ability. This research is expected to be able to increase the reference of a coach to improve the ability to shot put of his athletes.
\end{abstract}

Keywords: heavy bag thrust; shot put 


\section{PENDAHULUAN}

Olahraga prestasi merupakan olahraga yang lebih menekankan pada peningkatan prestasi seorang atlet pada suatu kecabangan olahraga tertentu. Melalui olahraga prestasi ini dapat dikembangkan potensi diri atau bakat dari atlet bersangkutan. Olahraga prestasi juga berperan penting dalam pengembangana aspek kepribadian atlet seperti tanggung jawab, kompetisi, disiplin dan percaya diri. Ada banyak olahraga yang dapat dijadikan sebagai olahraga prestasi salah satunya adalah atletik.

Atletik adalah induk dari semua cabang olahraga yang berisikan latihan fisik yang lengkap, menyeluruh, dan mampu memberikan kepuasan kepada manusia atau terpenuhinya dorongan nalurinya untuk bergerak, namun tetap mematuhi suatu disiplin dan aturan main (Wijayanti dalam Candra \& Wawan, 2020). Atletik terdiri atas nomor lari, lempar dan lopat yang kesemuanya merupakan bagian dari pergerakan umum eseorang sehari-hari.

Salah satu nomor dalam atletik adalah tolak peluru. Sesuai dengan namanya maka tolak peluru tidak dilempar tetapi ditolak atau didorong, yaitu dorongan dari bahu yang kuat disertai dengan gerakan merentangkan lengan, pergelangan tangan, dan jari-jari yang terarah dengan tujuan agar didapat jarak tolakan yang maksimal (Jarver, 1999). Teknik tolak peluru adalah semata-mata satu metode penolakan dengan satu tangan. Ketika menolak dengan mengambil sikap berdiri dengan diameter lingkaran 2,135 meter untuk memulai tolakan, peluru harus dekat dengan bahu atau dagu. Selama menolak peluru tidak boleh diletakkan dibelakang bahu. Transisi dari luncuran tolakkan yang sebenarnya dapat disempurnakan dengan gaya gerak. Adapun sudut lepas 400 (Adisasmita, 1986).

Sekolah merupakan tempat terjadinya proses pembelajaran. Pembelajaran merupakan bantuan yang diberikan pendidik agar dapat terjadi proses perolehan ilmu dan pengetahuan, penguasaan kemahiran serta pembentukan sikap dan kepercayaan pada peserta didik (Rosdiani dalam Prabowo, 2018). Kualitas pembelajaran Pendidikan Olahraga, di sekolah sangat dipengaruhi berbagai unsur, antara lain guru sebagai unsur utama siswa, kurikulum, tujuan, metode, sarana dan prasarana, penilaian, dan suasana kelas (Sari dalam Suastri, 2019). Sekolah sendiri merupakan awal dari seorang pendidik dalam memperkenalkan olahraga yang salah satunya adalah atletik nomor tolak peluru.

Tolak peluru tidak hanya sekedar diajarkan sebagai salah satu bagian dari mata pelajaran pendidikan jasmani olahraga dan kesehatan disekolah-sekolah. Namun tolak peluru merupakan salah satu nomor atletik yang selalu diperlombakan pada perlombaan tingkat internasional dan nasional. Pembinaan prestasi olahraga melalui kegiatan disekolah dapat digunakan sebagai pembinaan olahraga prestasi. Tujuan dari pembinaan olahraga prestasi ini yaitu untuk menjaring siswa siswa yang kompoten sejak dini, sehingga dapat dilakukan pembinaan lebih awal dan dapat dilakukan secara berjenjang.

Siswa Sekolah Menengah Pertama (SMP) merupakan salah satu jenjang dalam rangka pemilihan dan pembinaan prestasi tolak peluru sejak dini agar dapat melakukan tolakan dengan baik diperlukan upaya pelatihan yang sitematis, kontinyu dan prograsif dari seorang siswa SMP. Siswa SMP dalamtahapan ini disebut juga dengan "multi-event" yang semuanya mulai belajar untuk bagaimana berlatih dengan pembentukan kemampuan dasar (Thompson, 2009). Selain hal itu pembinaan yang jelas dan terarah juga akan menjadikan siswa siswa SMP menjadi bibit unggulan dalam olahraga tolak peluru. Sebagai tuntutan dalam pembinaan yang terarah dengan jelas tampak pada penyusunan program latihan dan metode latihan yang dilakukan.

Tolak peluru yang sering diajarkan oleh pelatih ekstrakulikuler SMP Negeri 5 Kota Gorontalo yaitu tolak peluru gaya menyamping. Tolak peluru gaya menyamping dinilai sesuai dengan 
kemampuat anak SMP. Tahapan gerakan meliputi persiapan, gelincir, pelepasan, dan pemulihan (IAAF, 2000).

SMP Negeri 5 Kota Gorontalo merupakan salah satu SMP yang melakukan pembinaan atlet tolak peluru yang dilakukan melalui kegiatan ekstrakulikuler. Problematika yang penulis temui dilapangan pada saat melakukan observasi yaitu kurangnya power otot lengan yang menjadi salah satu penyebab hasil tolakan menjadi tidak optimal. Menurut Mylsidayu \& Kurniawan (2015) power dapat diartikan sebagai kekuatan dan kecepatan yang dilakukan bersama-sama dalam melakukan suatu gerak. Kegiatan tolak peluru ini dikategorikan sebagai power asiklis yang dilakukan secara cepat dan kuat dalam atu kali gerakan (Suharjana, 2013). Maka, penulis berinisiatif untuk melakukan sebuah penelitian agar power otot lengan atlet dapat meningkat, yaitu dengan suatu latihan.

Latihan heavy bag merupakan salah satu latihan yang dapat meningkatkan power otot lengan. Latihan ini membutuhkan sebuah karung tinju yang digantung memakai tali atau kabel yang melibatkan otot trisep, pectorals, deltoid, biceps, trapezius, abdominal, actiternal, obliges, dan otot pinggul ekstensor. Latihan ini cocok digunakan untuk olahraga pelempar cakram, tolak peluru, angkat besi serta sepak bola dan bola basket.

\section{METODE PENELITIAN}

Metode penelitian ini menggunakan eksperimen dengan desain penelitian one group pre-test and post-test design. Data dikumpulkan menggunakan pre-test dan post-test. Populasi dalam penelitian ini adalah siswa ekstrakulikuler SMPN 5 Kota Gorontalo berjumlah 27. Sedangkan sampel penelitian ini adalah sebagian dari jumlah populasi yang berjumlah 23 orang.

\section{HASIL PENELITIAN}

Dari hasil penelitian pada pre test dan post test pengaruh latihan heavy bag thrust terhadap kemampuan tolak peluru siswa ekstrakulikuler SMP N 5 Kota Gorontalo diperoleh frekuensi sebagai berikut:

Tabel 1. Data Hasil Penelitian Pre Test dan Post Test Kemampuan Tolak Peluru

\begin{tabular}{|c|c|c|c|}
\hline No & $\mathbf{X}_{\mathbf{1}}$ & $\mathbf{X}_{\mathbf{2}}$ & Gain (d) \\
\hline 1 & 7.54 & 8.05 & 0.51 \\
\hline 2 & 6.3 & 6.5 & 0.2 \\
\hline 3 & 6.48 & 7.35 & 0.87 \\
\hline 4 & 7.55 & 8.12 & 0.57 \\
\hline 5 & 7.24 & 7.98 & 0.74 \\
\hline 6 & 4.59 & 5.3 & 0.71 \\
\hline 7 & 5.44 & 6.42 & 0.98 \\
\hline 8 & 8.05 & 8.87 & 0.82 \\
\hline 9 & 7.9 & 8.43 & 0.53 \\
\hline 10 & 5.88 & 6.7 & 0.82 \\
\hline 11 & 5.34 & 5.8 & 0.46 \\
\hline 12 & 7.16 & 7.4 & 0.24 \\
\hline 13 & 6.73 & 6.8 & 0.07 \\
\hline 14 & 6.49 & 6.7 & 0.21 \\
\hline
\end{tabular}




\begin{tabular}{|c|c|c|c|}
\hline 15 & 6.82 & 7.5 & 0.68 \\
\hline 16 & 4.93 & 4.3 & -0.63 \\
\hline 17 & 6.57 & 6.85 & 0.28 \\
\hline 18 & 6.7 & 5.5 & -1.2 \\
\hline 19 & 4.53 & 5.73 & 1.2 \\
\hline 20 & 7.47 & 7.8 & 0.33 \\
\hline 21 & 6.15 & 6.39 & 0.24 \\
\hline 22 & 4.35 & 4.5 & 0.15 \\
\hline 23 & 7.15 & 7.19 & 0.04 \\
\hline J & $\mathbf{1 4 7 . 3 6}$ & $\mathbf{1 5 6 . 1 8}$ & $\mathbf{8 . 8 2}$ \\
\hline R & $\mathbf{6 . 4 0 6 9 5 7}$ & $\mathbf{6 . 7 9 0 4 3 5}$ & $\mathbf{0 . 3 8 3 4 7 8}$ \\
\hline SD & $\mathbf{1 . 0 9 8 0 8 3}$ & $\mathbf{1 . 2 0 5 8 8 5}$ & $\mathbf{0 . 5 2 0 6 6}$ \\
\hline V & $\mathbf{1 . 2 0 5 7 8 6}$ & $\mathbf{1 . 4 5 4 1 5 9}$ & $\mathbf{0 . 2 7 1 0 8 7}$ \\
\hline
\end{tabular}

Sumber: Data Primer

Dengan melihat hasil perolehan data dari tes awal dan tes akhir penelitian tentang kemampuan tolak peluru siswa ekstrakulikuler SMP Negeri 5 Kota Gorontalo dengan penerapan latihan heavy bag thrust ternyata dapat meningkatkan kemampuan tolak peluru pada cabang olahraga atletik. Hal ini dapat dilihat dari peningkatan rata-rata sebelum diberikan latihan sebesar 6,41 dan sesudah diberikan latihan sebesar 6,79 sehingganya rata-rata peningkatan sebesar 0,38. Berdasarkan hasil tersebut, peneliti beranggapan bahwa latihan heavy bag thrust ini dapat meningkatkan kemampuan tolak peluru pada cabang olahraga atletik.

\section{PEMBAHASAN}

Proses latihan dengan menggunakan bentuk latihan heavy bag thrust memiliki pengaruh positif terhadap peningkatan kemampuan tolak peluru pada siswa SMP Negeri 5 Kota Gorontalo yang diawali dengan pemberian suatu penjelasan tentang bentuk latihannya serta penjelasan tentang cara melakukannya dengan baik dan benar. Latihan power ini merujukpada kemampuan melakukan gerakan dengan cepat sehingga bila tahanan yang dihadapi tidak mampu digerakkan dengan cepat maka kekuatan kecepatan akan menjadi kekuatan eksplosif (Lumintuarso, 2013). Eksplosif terebutlah yang diharapkan dapat menambah kemampuan sisiwa. Setelah itu siswa sebagai sampel melakukan latihan dengan baik dan benar sebagaimana yang telah dicontohkan yaitu latihan heavy bag thrust sesuai dengan program latihan yang sudah dirancang sebelumnya.

\section{KESIMPULAN}

Dari penelitian ini dapat diungkapkan bahwa latihan heavy bag thrust dapat memberikan pengaruh positif terhadap peningkatan kemampuan tolak peluru siswa SMP Negeri 5 Kota Gorontalo. Latihan ini diharapkan dapat menjadi salah satu sumbr referensi bagi pelatih agat dapat meningkatkan kemampuan atletik nomor lempar pada umumnya dan untuk khususnya nomor tolak peluru.

\section{REFERENSI}

Adisasmita, M, Y. (1986). Atletik dan Metodik. Jakarta: Karunika Jakarta Universitas Terbuka.

Candra, A, T., Wawan, S. (2020). Meningkatkan Hasil Belajar Tolak Peluru Gaya Menyamping Menggunakan Alat Bantu Modifikasi Bola Kasti. Jurnal Pendidikan Kesehatan Rekreasi, 6(1). 25-30. https://doi.org/10.5281/zenodo.3661567. 
IAAF. (2000). Pedoman Mengajar Lari, Lempar, Lompat. Jakarta: IAAF.

Jarver, J. (1999). Atletik. Bandung: CV Pioneer.

Lumintuarso, R. (2013). Teori Kepelatihan Olahraga. Jakarta: LANKOR.

Mylsidayu, A., \& Kurniawan, F. (2015). Ilmu Kepelatihan Dasar. Bandung: Alfabeta.

Prabowo, E, M. (2018). Meningkatkan Keterampilan Tolak Peluru Gaya Menyamping dengan Permainan Modifikasi pada Siswa Kelas VIII A SMP Negeri 1 Bareng Kecamatan Bareng Kabupaten Jombang. JURNAL KOULUTUS, 1(2) p. 140-163, oct. 2018. ISSN 2620-6277. Available at: <http://ejournal.kahuripan.ac.id/index.php/koulutus/article/view/144>. Date accessed: 29 feb. 2020.

Suastri, N, K. (2019). Upaya Meningkatkan Hasil Belajar Atletik Tolak Peluru Gaya Menyamping. Jurnal Imiah Pendidikan dan Pembelajaran, 3(2). 222-229

Suharjana. (2013). Kebugaran Jasmani. Yogyakarta: Jogja Global Media.

Thompson, P, J, L. (2009). Introduction to Coaching. UK: IAAF. 